\title{
Innovation In solid Mechanics Laboratory
}

\author{
Dr. Moujalli Hourani \\ Associate Professor \\ Department of Civil Engineering \\ Manhattan College \\ Riverdale, New York
}

\section{Abstract}

This paper presents an innovative approach adopted by the civil engineering department in the Solid Mechanics Laboratory Course "ENGS 231" to implement item b of criterion 3. "Program Outcomes and Assessment" of ABET 2000. Item b states "Engineering Programs must demonstrate that their graduates have the ability to design and conduct experiment, as well as to analyze and interpret data". The innovative approach is a project consisting of designing, constructing, and testing of structural systems made of different materials, and subjected to different loading and support conditions. The paper presents the detailed description of the project, all the steps performed by the students, and the difficulties faced by the students in their first attempt of this project. In addition, the paper concentrates on the Outcomes and the Assessments of the project according to criterion 3.of ABET 2000.

Introduction

In the fall of 2002 the school of engineering programs at Manhattan College have gone through the accreditation process under the ABET Engineering Criteria 2000. Few years ago the Civil Engineering Department started a critical review of all aspects of its program to determine the changes, or enhancements needed to satisfy Criterion 1-8. The outcomes of the review proved that our program satisfied the majority of the ABET 2000 criteria. The only area of concern was item b of Criterion 3. Program Outcomes and Assessment "Engineering programs must demonstrate that their graduates have the ability to design and conduct experiments, as well as to analyze and interpret data". The department's discussions and debates focused on the appropriate year in undergraduate education to achieve this goal. The department spent a considerable amount of time studying the background in mathematics, sciences, and engineering sciences, which the students must have before making them designing and conducting experiments.

After further studies the department decided that ENGS 231 "Solid Mechanics Laboratory" is the most suitable course to implement the new changes. The students enrolled in this course will have completed the following: (1) at least three courses in mathematics, (2) at least three courses in sciences; (3) at least three courses in engineering science, including Statics, 
Thermodynamics, Dynamics, and Solid Mechanics.

The ENGS 231 is a one credit, required course, for the Civil Engineering students. The maximum number of students in the class is 15 . In the laboratory, a group of three students perform experiments to understand the strength and the behavior of an individual structural member subjected to tensile, torsional, compressive, or bending force. Last year we decided to focus our attention on the testing of structural systems such as continuous beams and trusses made of different materials, and subjected to different loading conditions.

This paper describes a group-based project in the Solid Mechanics Laboratory course to test models, of truss systems and continuous beams. The systems are made of different materials, and subjected to different loading and support conditions. For the truss, the objective of the experiment is to determine experimentally the loading capacity of each member, the joint displacements, and the failure mode. For the continuous beam, the objective of the experiment is to determine the transverse deflection at several points due to various loading conditions, and to demonstrate the compatibility conditions at the interior supports.

\section{Project Description}

The truss project consisted of a truss system shown in figure 1. Each group was required to build a truss made of different material and cross-sectional properties.

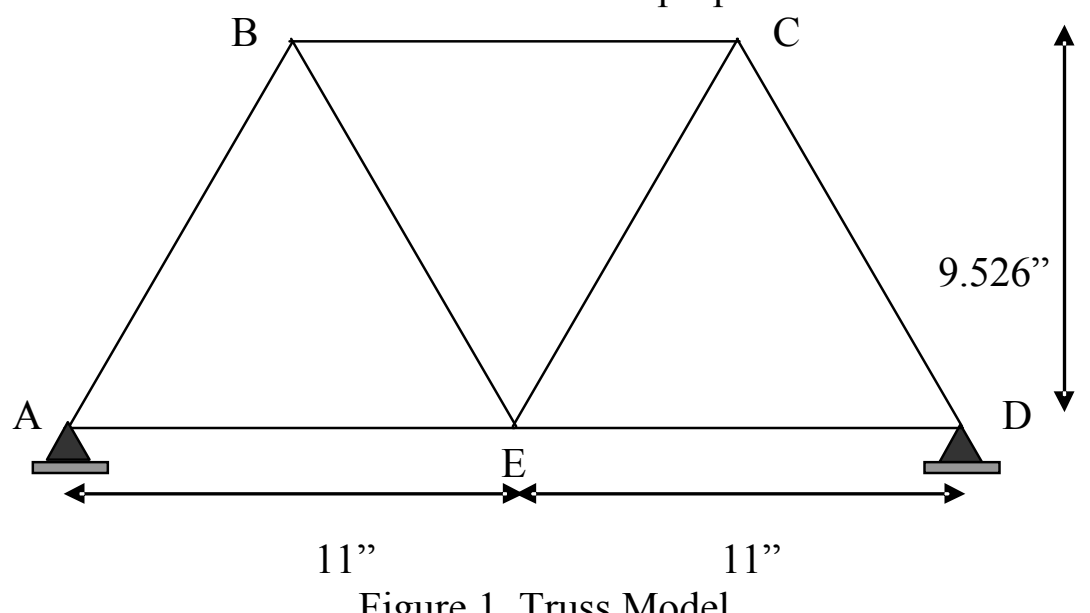

Figure 1. Truss Model

The first model truss of two equal-leg steel angles $2 \mathrm{~L} 1.5$ " X 1.5" $\mathrm{X} 1 / 8$ " as shown in figure 2 was constructed by the lab technician and the graduate students to be used to demonstrate the construction technique in sizing the members, sizing and drilling the gusset plate and assuring concentric connection of the members to the gusset plates.

Each group had one week to decide on the type of the material and the size of the crosssectional properties to be used in the project. We end up with five different proposed trusses; one steel truss with a pair of equal-leg angles $2 \mathrm{~L} 1$ " X 1 " X 1/8", two aluminum trusses $2 \mathrm{~L} 1.5$ " X 1.5 " X 1/8", and 2L 1" X 1" X 1/8", and two wood-trusses oak 1" X 1", and pine 1" X 1". Each group was responsible to size the members, construct the gusset plate with all the required holes, select the type of fasteners, and to build-up the truss and have ready to be tested (DESIGN).

"Proceeding of the 2003 American Society for Engineering Education Annual Conference \& Exposition Copyright? 2003, American Society for Engineering Education" 


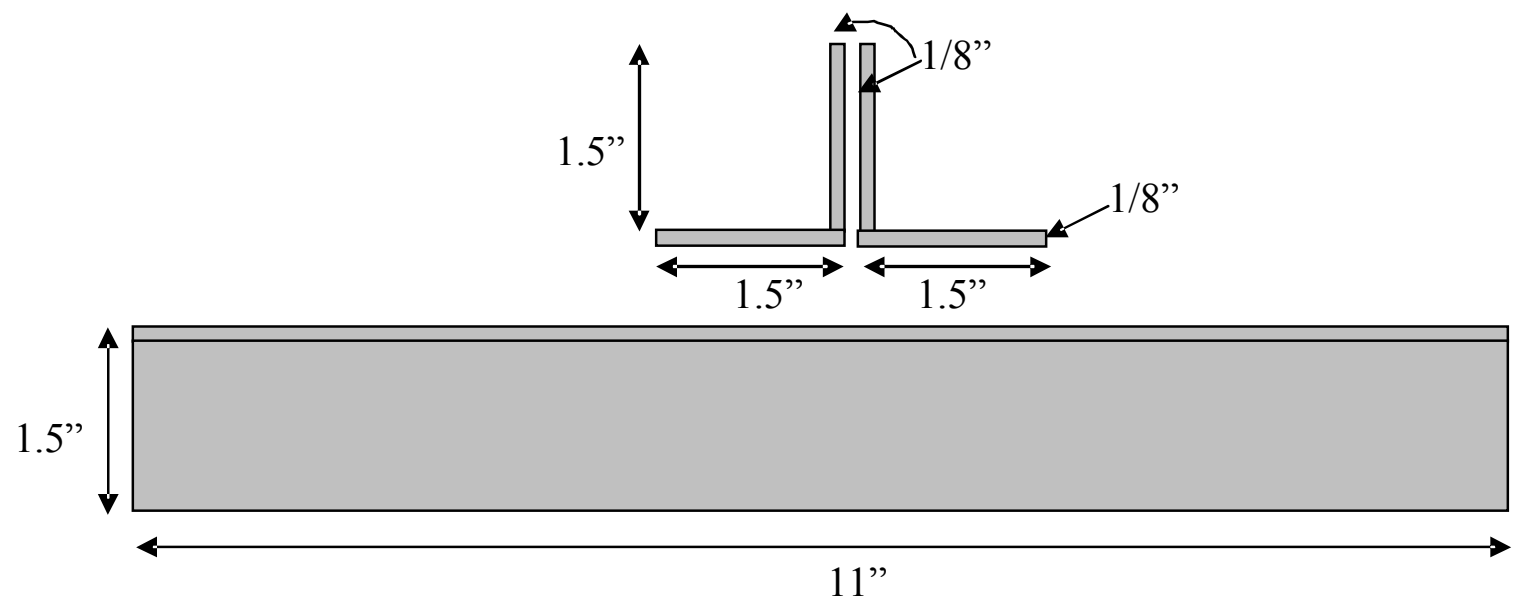

Experimental Work

Figure 2. Geometry of a member

The testing of the trusses was done in the Solid Mechanics Laboratory under the supervision of a professor, a lab technician and a graduate student to ensure that all participants followed all Safety Regulations. Strain gages were attached to specific members and connected to digital strain indicators, and two dial gages were placed in different positions at node $\mathrm{C}$ and $\mathrm{E}$ to measure the vertical and the horizontal displacements. The testing apparatus is a Hampden Model h-6320 Structures Test System, consisting of a framed base, a hydraulic pump, and dial indicators. The maximum span of a tested structure is 29.5 " center-to-center.

Each group had their truss ready to be fastened to the testing machine, and a vertical load was gradually applied at joint $\mathrm{E}$ up to a certain limit set-forth before the start of the experiment.

\section{(CONDUCT EXPERIMENT)}

Data collected from the strain indicators and the dial gages were used to compare the experimental results to the theoretical results. Each group had developed a spreadsheet program shown below, to calculate the stresses in all members and the displacements at the nodes.

(ANALYZE AND INTERPRET DATA)

\begin{tabular}{|c|c|c|c|c|c|c|c|c|c|c|}
\hline \multirow[b]{2}{*}{ Member } & \multicolumn{3}{|r|}{$P=$} & \multicolumn{2}{|c|}{\begin{tabular}{|l|}
20000 \\
Ibs
\end{tabular}} & $\begin{array}{c}E= \\
\text { Axial }\end{array}$ & \multicolumn{4}{|c|}{$3.00 \mathrm{E}+07 \mathrm{psi}$} \\
\hline & $\mathbf{L}$ & A & $\mathbf{F}$ & $\sigma_{\mathrm{x}}$ & $\Delta$ & $\varepsilon_{\mathbf{X}}$ & $U_{c}$ & $\left(\Delta_{\mathrm{y}}\right)_{\mathrm{C}}$ & $U_{E}$ & $\left(\Delta_{\mathrm{y}}\right)_{\mathrm{E}}$ \\
\hline & in & in $^{2}$ & lbs & psi & in & in/in & lbs & in & lbs & in \\
\hline$A B$ & 11 & 0.719 & $-1.15 E+04$ & $-1.61 E+04$ & -0.0059 & $-5.36 \mathrm{E}-04$ & -0.866 & 0.005 & -0.577 & 0.003 \\
\hline$B C$ & 11 & 0.719 & $-1.15 \mathrm{E}+04$ & $-1.61 E+04$ & \begin{tabular}{|l|}
-0.0059 \\
\end{tabular} & \begin{tabular}{|c|}
$-5.36 \mathrm{E}-04$ \\
\end{tabular} & -0.500 & 0.003 & -0.577 & 0.003 \\
\hline$C D$ & 11 & 0.719 & $-1.15 E+04$ & $-1.61 E+04$ & -0.0059 & \begin{tabular}{|l|}
$-5.36 \mathrm{E}-04$ \\
\end{tabular} & -0.289 & 0.002 & -0.577 & 0.003 \\
\hline $\mathrm{DE}$ & 11 & $0.7 P r 9$ & eestim & he $8.08 \mathrm{~g} E+6 \mathrm{Bg}$ & erte:00 & 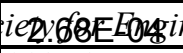 & eeringt4d & atopo00 & $a b .289$ & 0001 \\
\hline EA & 11 & ocpprge & rensygkt & positibiste 463 & pyoiglot? & 003.68 m9oica & nSocisgof & Eo:ojoper & $n g 0.289$ & 0.001 \\
\hline EB & 11 & 0.719 & $1.15 \mathrm{E}+04$ & $1.61 \mathrm{E}+04$ & 0.60659 & tig.36E-04 & -0.289 & -0.002 & 0.577 & 0.003 \\
\hline EC & 11 & 0.719 & $1.15 E+04$ & $1.61 \mathrm{E}+04$ & 0.0059 & $5.36 \mathrm{E}-04$ & 0.289 & 0.002 & 0.577 & 0.003 \\
\hline $\mathbf{S}$ & & & & & & & & 0.01145 & & 0.01871 \\
\hline
\end{tabular}


$\mathrm{L}=$ length of the member in inches.

$\mathrm{A}=$ Cross-sectional area of the member in square inches.

$\mathrm{F}=$ Force in the member in lbs.

$\sigma_{\mathrm{x}}=$ Axial stress in the member $=\mathrm{F} / \mathrm{A}$, in psi.

$\Delta=$ Axial deformation in the member $=\mathrm{F}^{*} \mathrm{~L} /(\mathrm{A} * \mathrm{E})$, in inches.

$\varepsilon_{\mathrm{x}}=$ Axial strain in the member $=\Delta / \mathrm{L}$, in in/in.

$\mathrm{U}_{\mathrm{C}}=$ Force in the member due to a virtual unit vertical load applied at Joint $\mathrm{C}$.

$\left(\Delta_{\mathrm{y}}\right)_{\mathrm{C}}=$ Vertical deflection at $\mathrm{C}$ in inches $=\sum \mathrm{F}^{*} \mathrm{U}_{\mathrm{C}} * \mathrm{~L} /\left(\mathrm{A}^{*} \mathrm{E}\right)$

$\mathrm{U}_{\mathrm{E}}=$ Force in the member due to a virtual unit vertical load applied at Joint $\mathrm{E}$.

$\left(\Delta_{\mathrm{y}}\right)_{\mathrm{E}}=$ Vertical deflection at $\mathrm{E}$ in inches $=\sum \mathrm{F}^{*} \mathrm{U}_{\mathrm{E}} * \mathrm{~L} /(\mathrm{A} * \mathrm{E})$

The continuous beam project for the spring 2002 semester, consisted of:

1- Construction of a continuous beam with different support conditions.

2- Testing the beam to determine the vertical deflection at any point along the beam.

3- Comparing the experimental and theoretical results.

4- $\quad$ Each group will be assigned a continuous beam made of wood or steel.

5- $\quad$ The group is required to construct the beam, and the support mechanisms.

6- $\quad$ The group is required to write the manual for the experiment.

7- $\quad$ The group is required to participate in a technical presentation to describe the project.

8- $\quad$ The base of the support at B, C \& D must be able to slide in the supporting base to allow for the variation in the span lengths.

9- Any or all the supports at B, C, \& D must be removable to represent beam with different support conditions.

10- The support conditions must simulate a roller, a hinge, and a fixed end.

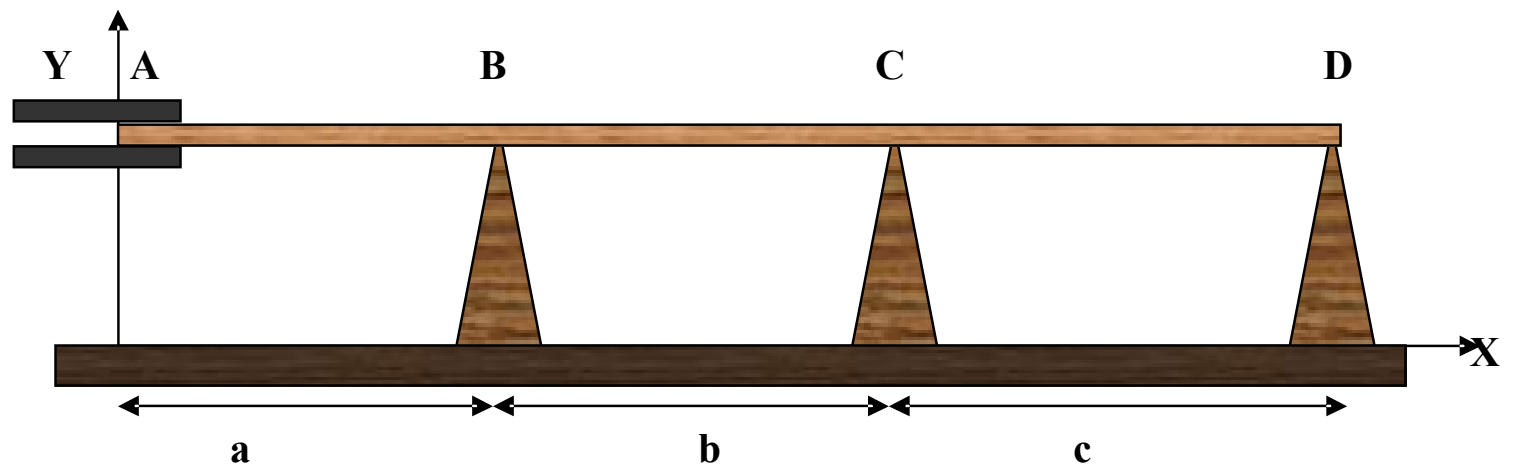

Figure 3. Beam System

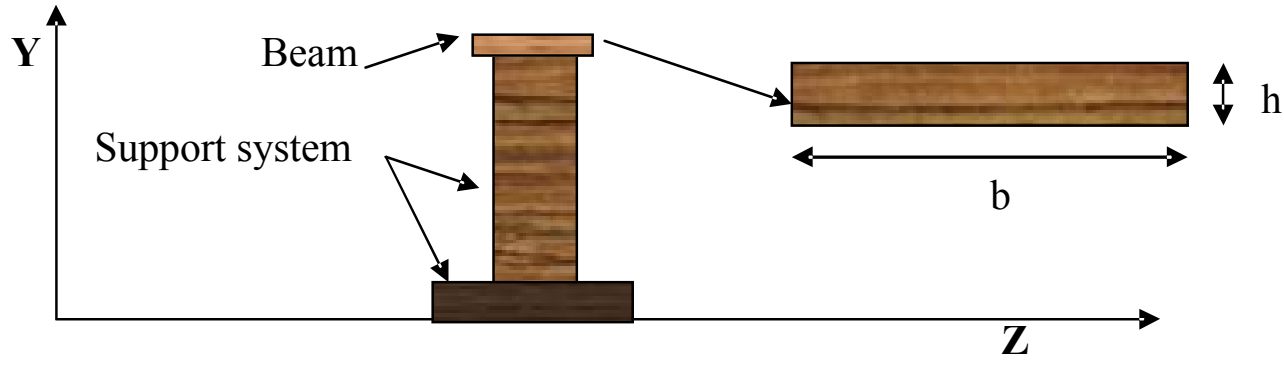

Figure 4. Side View

"Proceeding of the 2003 American Society for Engineering Education Annual Conference \& Exposition Copyright? 2003, American Society for Engineering Education" 
Five different beam systems were constructed. The support systems were built using wood, while the beam elements were made from various materials. A typical beam system is shown in figure 5. The ingenuity of the students was demonstrated in the design of the support mechanism to simulate fixed, roller and hinged support as shown in figures 6 and 7. A concentrated transverse load was applied at different locations along the beam and dial cages were used to measure the transverse deflections under the load and at others specific locations. The measured deflections were compared to the theoretical deflections by means of hand calculation using the Mathematical Model to analyze the beam and by using the RISA 2-D computer program. In addition the students observed the compatibility of the slope at the supports, and they were able to compare the measured value of the slope to the calculated value.

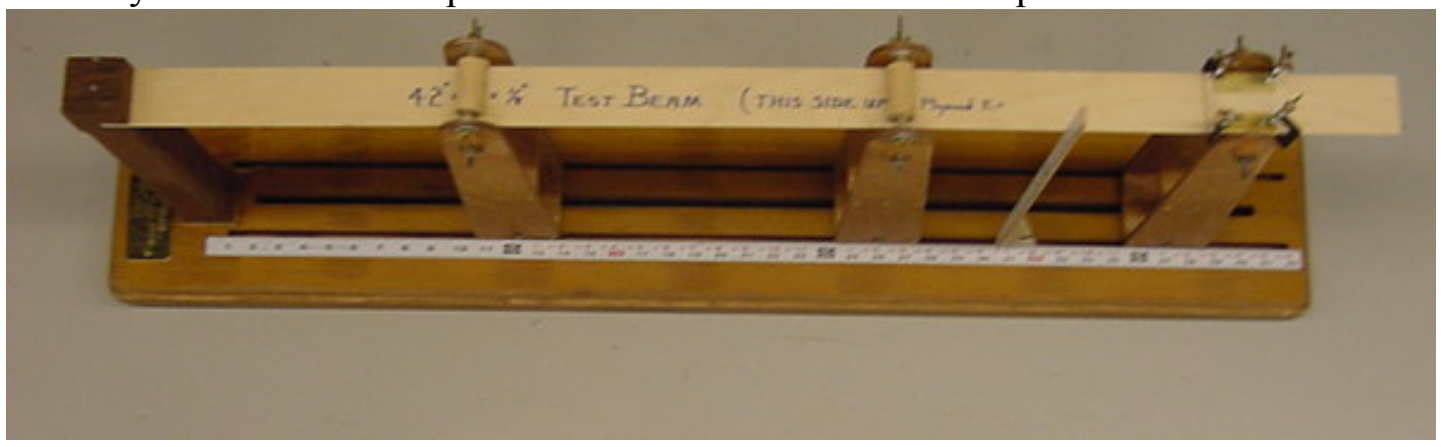

Figure 5. Sample Beam

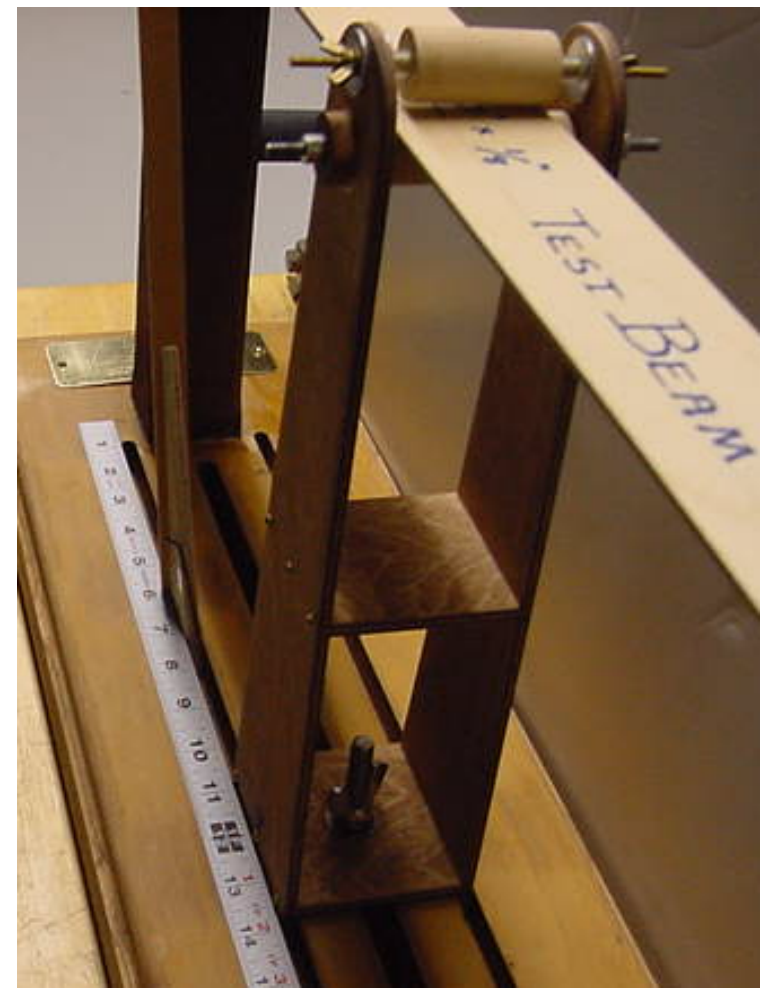

Figure 6. Roller Support

"Proceeding of the 2003 American Society for Engineering Education Annual Conference \& Exposition Copyright? 2003, American Society for Engineering Education" 


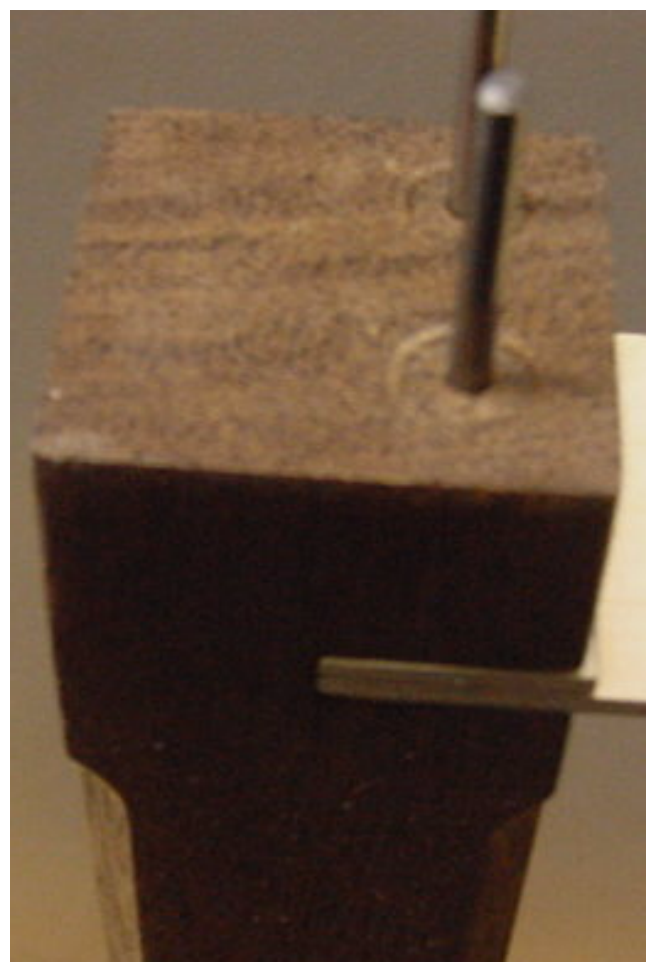

Figure 7. Fixed Support

One major component of the truss and the continuous beam project was that each group was required to write a detailed laboratory manual for the experiment. The manual included: (1) purpose, (2) introduction, (3) theory, (4) experimental procedures, and, (5) report writing requirements.

\section{Student's Response}

When the department decided to go ahead with this project, I had great concerns about the response of the students regarding the amount of time needed to build the truss or the continuous beam system, to conduct the experiment, and to prepare the manual. The positive response from the students was clearly demonstrated when they started asking the following questions: (1) "What will happen to the truss if we use one single angle in a particular member?", (2) "What will happen to the stress in a specific member if we use different crosssectional area for diagonal members?" (3) "Why the gusset-plate failed?" Most of the questions were answered experimentally in the laboratory by modifying the truss configuration. The continuous beam project presented the students with many challenging observations, and questions concerning the bending and the lateral buckling behaviors. The students faced difficulties putting the truss together, and aligning the holes for the fasteners in the gusset plate. In the beam experiment a considerable amount of time was spent on modeling the support mechanisms of the beam and the movable support in the base. The major complaint was the amount of work and time invested for one credit course. 


\section{Conclusion}

In this paper, an innovative approach in the Solid Mechanics Laboratory adopted by the Civil Engineering Department at Manhattan College is presented. The student's response to the project was excellent. Since all the students have had Solid Mechanics, the application of the theory to a real project was a natural process in learning. The Civil Engineering Department is very pleased with the project because it satisfies all components of Item b of Criterion 3 of ABET 2000.

The truss system and the beam system will be placed on a movable platform equipped with a computer to be used in the classroom in a lecture type setting. In conjunction with the computer modeling the experimental test will be perform to show the behavior of a truss or a continuous beam under various loading conditions.

\section{Biography}

Dr. MOUJALLI HOURANI is an associate professor of civil engineering at Manhattan College in New York. Dr. Hourani received his bachelor's degree from Manhattan College, a master degree from Rose Hulman Institute of Technology, and Doctor of Science degree from Washington University. Dr. Hourani's research experience includes: composite materials, finite elements, and reinforced concrete.

"Proceeding of the 2003 American Society for Engineering Education Annual Conference \& Exposition Copyright? 2003, American Society for Engineering Education" 